G. M. de. Resende

RESENDE, M.A.V. de; VIEIRA, R.F. Viabilidade do cultivo da ervilha no Norte de Minas Gerais. Horticultura Brasileira, Brasília, v. 17, n. 1, p. 60-64, março 1999.

\title{
Viabilidade do cultivo da ervilha no norte de Minas Gerais.
}

\author{
Maria Aparecida V. de Resende; Rogério F. Vieira \\ EPAMIG, Vila Gianetti, casa 47, 36571-000 Viçosa - MG.
}

\section{RESUMO}

Com o objetivo de estudar a viabilidade de se cultivar ervilha destinada à produção de grãos secos e verdes no norte de Minas Gerais, foram conduzidos dois ensaios de competição entre cultivares na fazenda experimental da EPAMIG, em Janaúba. O primeiro ensaio foi instalado em 16 de maio de 1995 e foram avaliadas 20 cultivares e linhagens. O segundo ensaio foi instalado em 15 de maio de 1997 e foram testadas 15 cultivares e linhagens. A ervilha foi plantada no espaçamento entre fileiras de $30 \mathrm{~cm}$, utilizando-se 30 sementes por metro. Os ensaios foram conduzidos em solo de média a alta fertilidade e fez-se adubação com 90,140 e $80 \mathrm{~kg} / \mathrm{ha}$ de $\mathrm{N}$, $\mathrm{P}_{2} \mathrm{O}_{5}$ e $\mathrm{K}_{2} \mathrm{O}$, respectivamente. Os ensaios foram irrigados por aspersão convencional, e foram utilizados defensivos químicos (fungicidas, inseticidas e nematicidas). As temperaturas médias durante a condução do ensaio de 1995 foram mais altas que as de 1997 e representaram bem as variações de temperatura do local. A emergência das plântulas deu-se com seis ou nove dias. Dependendo da cultivar e do ano, o florescimento teve início entre 23 e 45 dias após a emergência. A duração do período reprodutivo (início da floração à colheita) variou de 32 a 57 dias. $\mathrm{O}$ ciclo de vida, contado a partir da emergência, variou de 58 a 96 dias. Os rendimentos máximos alcançados foram 2,5 t/ha, em 1995, e 2,4 t/ha, em 1997, com uma taxa de produção máxima de $42,9 \mathrm{~kg} / \mathrm{ha} / \mathrm{dia}$, obtida em $1995 \mathrm{com}$ a cultivar precoce Majestic. Portanto, é viável o cultivo da ervilha no Norte de Minas Gerais ou em locais onde as condições edafoclimáticas forem semelhantes às de Janaúba.

Palavras-chave: Pisum sativum, produtividade, ciclo de vida.

\begin{abstract}
Viability of pea cultivation in the North of Minas Gerais State, Brazil.

Two trials were carried out at Janaúba (Northern Minas Gerais State) to evaluate the viability of dry pea (smooth and wrinkled seed coat) cultivation in this semi-arid region. The 1995 trial of 20 cultivars or lines was set up on May 16. The 1997 trial was set up on May 15, testing 15 materials. Thirty seeds per meter were planted in rows 0.3 $\mathrm{m}$ apart. Trials were set up on soil of medium to high fertility and peas were fertilized with 90,140 , and $80 \mathrm{~kg} / \mathrm{ha}$ of $\mathrm{N}_{2} \mathrm{P}_{2} \mathrm{O}_{5}$, and $\mathrm{K}_{2} \mathrm{O}$, respectively. Trials were irrigated by a solid set irrigation system and protected against fungi, insects, and nematodes by pesticides. The average temperatures during the pea life cycle in 1995 were milder than in 1997, and represented well the local temperature variations. Plant emergence occurred six or nine days after sowing. Depending on cultivar and year, flowering began between 23 and 45 days after emergence. The reproductive period varied from 32 to 57 days; life cycle (emergence to harvest) varied from 58 to 96 days. Maximum yield attained was $2,486 \mathrm{~kg} / \mathrm{ha}$ in 1995 , and 2,363 kg/ha in 1997 , with a maximum production rate of $42.9 \mathrm{~kg} / \mathrm{ha} /$ day achieved in 1995 with the early cultivar Majestic. Pea is therefore a viable crop for Northern Minas Gerais or in regions where climate and soil conditions resemble those of Janaúba.
\end{abstract}

Keywords: Pisum sativum, yield, life cycle.

(Aceito para publicação em 09 de novembro de 1998) 
A ervilha (Pisum sativum L.) é cultivada em regiões de clima temperado, mas também pode ser explorada perto da linha do equador, quando a altitude compensa a latitude desfavorável. As temperaturas aproximadas para o êxito no cultivo da ervilha são: mínima, entre $0^{\circ} \mathrm{C}$ e $5^{\circ} \mathrm{C}$; ótima, entre $25^{\circ} \mathrm{C}$ e $31^{\circ} \mathrm{C}$; e máxima, entre $31^{\circ} \mathrm{C}$ e $37^{\circ} \mathrm{C}$ (Arnold, 1959, citado por Reis et al., 1989). Em Minas Gerais, a ervilha é plantada no outono, época em que há escassez de chuvas. Por isso, é imprescindível o uso da irrigação.

As cultivares de ervilha são classificadas, quanto à sua utilização principal, em seis grupos (Giordano, 1989a): 1) grãos secos, 2) grãos verdes para enlatamento, 3) grãos verdes para congelamento, 4) grãos verdes debulhados para consumo "in natura", 5) vagens do tipo comestível, e 6) forragem. As cultivares utilizadas para a produção de grãos secos possuem sementes redondas e lisas, e apresentam teor de amido mais elevado que as cultivares utilizadas para produção de grãos verdes para enlatamento. Elas são utilizadas para produção de ervilha partida ou na indústria de reidratação. As cultivares destinadas à industrialização de grãos verdes possuem, em geral, grãos rugosos e elevado teor de açúcar. Algumas cultivares cujos grãos imaturos têm coloração verde-intensa, como a Bolero, são produzidas para congelamento (Giordano, 1989a).

Em Minas Gerais, além do feijãocomum (Phaseolus vulgaris L.), o cultivo da ervilha para produção de grãos secos e verdes tem sido a opção de cultivo no outono-inverno, principalmente na região do Alto Paranaíba e do Triângulo Mineiro. A cultivar Mikado é a mais utilizada para a produção de grãos secos, ao passo que a Bolero é a mais cultivada para a produção de grãos verdes para congelamento. Nas lavouras bem conduzidas nessas regiões são alcançados rendimentos de grãos secos superiores a $2.500 \mathrm{~kg} / \mathrm{ha}$. Estudo conduzido por Guaresqui (1982) demonstra a viabilidade do cultivo de ervilha também na região sul de Minas Gerais, onde ele conseguiu $1.833 \mathrm{~kg} / \mathrm{ha}$, média superior à do Rio Grande do Sul (1.200 $\mathrm{kg} / \mathrm{ha})$. No Planalto Central, onde o cul-

Tabela 1- Temperaturas $\left({ }^{\circ} \mathrm{C}\right)$ médias máximas e mínimas e temperaturas absolutas máximas e mínimas durante o período de condução dos ensaios. Janaúba, EPAMIG, 1995/1997.

\begin{tabular}{lcccc}
\hline & Maio & Junho & Julho & Agosto \\
\hline Ensaio de 1995 & & & & \\
Média das máximas & 32,4 & 30,2 & 29,7 & 31,3 \\
Média das mínimas & 20,6 & 17,0 & 18,2 & 17,4 \\
Máxima absoluta & 35,6 & 33,2 & 33,8 & 34,6 \\
Mínima absoluta & 17,4 & 10,4 & 12,4 & 13,2 \\
\hline Ensaio de 1997 & & & & \\
Média das máximas & 29,3 & 29,9 & 28,9 & 30,6 \\
Média das mínimas & 17,4 & 14,4 & 15,9 & 15,4 \\
Máxima absoluta & 32,2 & 32,8 & 31,8 & 35,8 \\
Mínima absoluta & 12,4 & 10,6 & 11,6 & 11,6 \\
\hline Período 1989-1994 & & & & \\
Média das máximas & 30,4 & 29,3 & 29,2 & 29,6 \\
Média das mínimas & 18,7 & 17,0 & 16,5 & 17,0 \\
Máxima absoluta & 34,0 & 33,3 & 33,7 & 35,0 \\
Mínima absoluta & 14,8 & 12,8 & 11,3 & 12,2 \\
\hline
\end{tabular}

tivo da ervilha expandiu-se a partir da década de 80 , a produtividade média de grãos secos é de $1.500 \mathrm{~kg} / \mathrm{ha}$ (Couto, 1989), mas pode atingir mais de 3.000 kg/ha (Galrão et al., 1974).

No norte de Minas, onde a área irrigada por aspersão vem se expandido, a ervilha é uma possível alternativa ao feijão-comum para compor um sistema de rotação de culturas no período de outono-inverno. No entanto, não há informações na literatura sobre o desempenho da ervilha nessa região. Portanto, o objetivo deste trabalho foi estudar a viabilidade de se cultivar ervilha destinada à produção de grãos secos e verdes no norte de Minas Gerais.

\section{MATERIAL E MÉTODOS}

Foram conduzidos dois ensaios na fazenda experimental da EPAMIG em Janaúba, norte de Minas Gerais. O primeiro ensaio foi instalado em 16 de maio de 1995 e foram testadas 20 cultivares e linhagens. O segundo ensaio foi instalado em 15 de maio de 1997 e foram testadas 15 cultivares e linhagens. O solo utilizado foi um Latossolo Vermelho-amarelo de classe textural fran- co-argilo-arenosa. A análise química do solo, realizada no laboratório de solos da EPAMIG de Janaúba, revelou, na camada de $0-20 \mathrm{~cm}$, o seguinte: $\mathrm{pH}$ $\left(\mathrm{H}_{2} 0\right)=6,0 ; \mathrm{Ca}=4,0 \mathrm{meq} / 100 \mathrm{~cm}^{3}, \mathrm{Mg}$ $=0,8 \mathrm{meq} / 100 \mathrm{~cm}^{3}, \mathrm{~K}=170 \mathrm{ppm}, \mathrm{P}=$ $21 \mathrm{ppm}$ e matéria orgânica $=0,9 \%$. A estação experimental está localizada numa altitude de $516 \mathrm{~m}$, na longitude $43^{\circ} 18^{\prime} \mathrm{W}$ e latitude $15^{\circ} 47^{\prime} \mathrm{S}$. As temperaturas médias verificadas durante a condução dos ensaios são apresentadas na Tabela 1. Nesta Tabela também são apresentadas as temperaturas médias do período de 1989-1994, que serão utilizadas para comparação com as ocorridas durante os anos de 1995 e 1997. Nas Tabelas 2 e 3 são listadas as cultivares e linhagens testadas em 1995 e 1997, respectivamente. As cultivares Majestic, Verde Templana e Polo PG1 foram obtidas no Instituto Agronômico de Campinas (IAC); as demais cultivares e linhagens, na Embrapa Hortaliças. As linhagens 91-016, 93-020 e 91-025, e a cultivar Bolero, são de sementes rugosas. Os outros materiais são de sementes lisas.

Foi utilizado o delineamento em blocos ao acaso, com quatro repetições. Cada parcela constou de quatro fileiras 
Tabela 2 - Resultados médios do ensaio de competição entre 20 cultivares/linhagens de ervilha. Janaúba, EPAMIG, 1995.

\begin{tabular}{|c|c|c|c|c|c|c|c|c|}
\hline $\begin{array}{l}\text { Cultivares/ } \\
\text { Linhagens }\end{array}$ & $\begin{array}{c}\text { Emerg. à } \\
\text { Floração } \\
\text { (dias) }\end{array}$ & $\begin{array}{l}\text { Período Re- } \\
\text { produtivo }^{1 /} \\
\text { (dias) }\end{array}$ & $\begin{array}{c}\text { Emerg. à } \\
\text { Colheita } \\
\text { (dias) }\end{array}$ & $\begin{array}{c}\text { Altura de } \\
\text { Plantas }^{2} / \\
\text { (cm) }\end{array}$ & $\begin{array}{c}\text { Estande } \\
\text { Final } \\
\left(2,4 \mathrm{~m}^{2}\right)\end{array}$ & $\begin{array}{l}\text { Rendimento } \\
\text { (kg/ha) }\end{array}$ & $\begin{array}{c}\text { Taxa de } \\
\text { Produção }^{3 /} \\
\text { /kg/ha/dia }\end{array}$ & $\begin{array}{c}\text { Peso de } \\
100 \text { Grãos } \\
\text { (g) }\end{array}$ \\
\hline Majestic & 23 & 35 & 58 & $60 \quad \mathrm{~d}$ & 136 abcd & $2.486 \mathrm{a}$ & 42,9 & 16,2 cde \\
\hline Verde Templana & 23 & 40 & 63 & 99 bcd & $154 \mathrm{ab}$ & $2.239 \mathrm{ab}$ & 35,5 & $21,2 \mathrm{ab}$ \\
\hline Jurema & 43 & 39 & 82 & $97 \mathrm{bcd}$ & $137 \mathrm{abcd}$ & $1.846 \mathrm{abc}$ & 22,5 & 12,5 efg \\
\hline CNPH 93-020 & 36 & 46 & 82 & $65 \mathrm{~cd}$ & 81 def & $1.841 \mathrm{abc}$ & 22,5 & $18,1 \mathrm{bc}$ \\
\hline Bolero & 43 & 41 & 84 & 86 bcd & 125 abcde & $1.793 \mathrm{abc}$ & 21,3 & $17,5 \mathrm{bc}$ \\
\hline CNPH 91-025 & 42 & 44 & 86 & $83 \mathrm{bcd}$ & 73 ef & $1.719 \mathrm{abc}$ & 20,0 & $17,6 \mathrm{bc}$ \\
\hline Polo PG1 & 42 & 42 & 84 & $92 \mathrm{bcd}$ & $145 \mathrm{abc}$ & $1.668 \mathrm{abc}$ & 19,9 & $23,2 \mathrm{a}$ \\
\hline Kodama & 44 & 42 & 86 & $112 \mathrm{~b}$ & 118 abcdef & $1.581 \mathrm{bc}$ & 18,4 & 14,5 cdefg \\
\hline Amélia & 44 & 40 & 84 & $85 \mathrm{bcd}$ & 134 abcd & $1.546 \mathrm{bcd}$ & 18,4 & $12,7 \quad$ efg \\
\hline CNPH 91-016 & 42 & 40 & 82 & 79 bcd & 82 def & $1.481 \mathrm{bcd}$ & 18,1 & $17,6 \mathrm{bc}$ \\
\hline Mikado & 44 & 42 & 86 & $114 \mathrm{~b}$ & $143 \mathrm{abc}$ & $1.245 \mathrm{~cd}$ & 14,5 & 13,7 defg \\
\hline Marina & 44 & 38 & 82 & $113 \mathrm{~b}$ & 112 abcdef & $1.232 \mathrm{~cd}$ & 15,0 & 13,3 \\
\hline Ivete & 42 & 42 & 84 & $164 \mathrm{a}$ & 101 bcdef & $1.207 \mathrm{~cd}$ & 14,4 & $11,7 \quad \mathrm{~g}$ \\
\hline Triofin & 45 & 41 & 86 & $103 \mathrm{bc}$ & 126 abcde & $1.185 \mathrm{~cd}$ & 13,8 & $17,0 \mathrm{~cd}$ \\
\hline Dileta & 44 & 43 & 87 & $107 \mathrm{bc}$ & 115 abcdef & $1.097 \mathrm{~cd}$ & 12,6 & 13,6 defg \\
\hline CNPH 86/083 & 43 & 43 & 86 & $100 \mathrm{bcd}$ & $63 \mathrm{f}$ & $1.062 \mathrm{~cd}$ & 12,3 & 12,5 \\
\hline Maria & 45 & 37 & 82 & $104 \mathrm{bc}$ & $166 \mathrm{a}$ & $1.017 \mathrm{~cd}$ & 12,4 & 12,1 \\
\hline Flávia & 42 & 42 & 84 & $95 \mathrm{bcd}$ & 128 abcde & $1.017 \mathrm{~cd}$ & 12,1 & 13,7 \\
\hline Luiza & 43 & 39 & 82 & $107 \mathrm{bc}$ & 130 abcde & $958 \mathrm{~cd}$ & 11,7 & 12,8 \\
\hline Viçosa & 44 & 45 & 89 & $109 \mathrm{~b}$ & $88 \quad$ cdef & $656 \mathrm{~d}$ & 7,4 & 15,5 cdef \\
\hline Média & 40,9 & 41,0 & 81,9 & 98,8 & 117,8 & $1.444,0$ & 18,3 & 15,4 \\
\hline C.V. $(\%)$ & - & - & - & 16,5 & 19,6 & 23,5 & - & 9,3 \\
\hline
\end{tabular}

*/ Médias seguidas da mesma letra nas colunas não diferem significativamente entre si a 5\% de probabilidade pelo teste de Tukey.

1/ Do início da floração à colheita.

2/ Tomada no vageamento. Média de 10 plantas.

3/ Rendimento dividido pelo ciclo de vida (emergência à colheita) da cultivar ou linhagem.

de $5 \mathrm{~m}$ de comprimento, espaçadas de $30 \mathrm{~cm}$, com 30 sementes por metro. Considerou-se, como área útil, as duas fileiras centrais, eliminando-se $50 \mathrm{~cm}$ das cabeceiras. Portanto, a área útil foi de $2,4 \mathrm{~m}^{2}$.

Na adubação de plantio foram utilizados $1.000 \mathrm{~kg} / \mathrm{ha}$ do formulado 4-14-8 $\left(\mathrm{N}-\mathrm{P}_{2} \mathrm{O}_{5}-\mathrm{K}_{2} \mathrm{O}\right)$. Também foi distribuído no sulco de plantio o inseticidanematicida granulado carbofuran, na dose de $20 \mathrm{~kg} / \mathrm{ha}$. Após a semeadura, uma calda do fungicida benomil $(0,5 \mathrm{~kg} /$ ha) foi pulverizada sobre as sementes. Em cobertura, em torno de 32 dias após a emergência (DAE), foram distribuídos, em filete, ao lado das fileiras de ervilha, $500 \mathrm{~kg} / \mathrm{ha}$ de sulfato de amônio. Em 1995, foram realizadas pulverizações com o inseticida malation (1 1/ha) misturado ao fungicida Cerconil (2 1/ha) aos 43, 60 e 75 DAE . Em 1997, os mesmos defensivos e doses foram aplicados aos 25, 39, 62 e 71 DAE. Os ensaios foram irrigados por aspersão convencional com base na evapotranspiração local, descontando-se a chuva do período. A lâmina de água total aplicada durante o ciclo de vida da ervilha ficou ao redor de $520 \mathrm{~mm}$. O controle de plantas daninhas foi feito com sacho durante a fase inicial de desenvolvimento das plantas, e, quando necessário, manualmente, quando as plantas já estavam bem desenvolvidas.

Foram tomados os seguintes dados: data de emergência, data de início e de final da floração, altura de plantas, estande final, data de colheita, rendimento de grãos secos e peso de 100 se- mentes. A data de início da floração foi anotada quando $50 \%$ das plantas da parcela tinham pelo menos uma flor aberta; e o final da floração, quando $50 \%$ das plantas não tinham mais flor. A altura de plantas foi tomada na fase de vageamento, medindo-se a distância entre a superfície do solo e a parte mais alta de cinco plantas esticadas, tomadas ao acaso em cada parcela. Considerouse período vegetativo o número de dias entre a emergência e o início de floração; período reprodutivo foi o número de dias entre o início da floração e a colheita da ervilha. Os dados de estande, altura de plantas, rendimento de grãos secos e peso de 100 sementes foram submetidos à análise de variância. Para a comparação entre médias foi utilizado o teste de Tukey, ao nível de 5\% de probabilidade. 
Tabela 3 - Resultados médios do ensaio de competição entre 15 cultivares/linhagens de ervilha. Janúba, EPAMIG, 1997.

\begin{tabular}{|c|c|c|c|c|c|c|c|c|}
\hline $\begin{array}{l}\text { Cultivares/ } \\
\text { Linhagens }\end{array}$ & $\begin{array}{c}\text { Emergência } \\
\text { à Floração } \\
\text { (dias) }\end{array}$ & $\begin{array}{l}\text { Período Re- } \\
\text { produtivo } 1 /^{\text {(dias) }}\end{array}$ & $\begin{array}{l}\text { Altura de } \\
\text { Plantas }{ }^{2} / \\
\text { (cm) }\end{array}$ & $\begin{array}{c}\text { Estande } \\
\text { Final } \\
\left(2,4 \mathrm{~m}^{2}\right)\end{array}$ & $\begin{array}{c}\text { Emergência } \\
\text { à Colheita } \\
\text { (dias) }\end{array}$ & $\begin{array}{c}\text { Rendimento } \\
\text { (kg/ha) }\end{array}$ & $\begin{array}{c}\text { Taxa de } \\
\text { Produção } \\
\text { /kg/ha/dia }\end{array}$ & $\begin{array}{l}\text { Peso de } \\
100 \text { Grãos } \\
\quad \text { (g) }\end{array}$ \\
\hline Dileta & 42 & 53 & $88 \mathrm{~b}$ & 67 & 95 & $2363 a$ & 24,9 & 15,7 de \\
\hline Marina & 42 & 51 & $102 \mathrm{~b}$ & $152 a b c$ & 93 & $2350 \mathrm{a}$ & 25,3 & $14,2 \mathrm{e}$ \\
\hline Polo PG1 & 39 & 53 & $107 \mathrm{~b}$ & 142 abcd & 92 & $2301 \mathrm{a}$ & 25,0 & $26,5 \mathrm{a}$ \\
\hline Mikado & 39 & 56 & $108 \mathrm{~b}$ & 76 efg & 95 & $2250 \mathrm{a}$ & 23,7 & $16,7 \mathrm{de}$ \\
\hline Amélia & 39 & 46 & $92 \mathrm{~b}$ & $157 \mathrm{ab}$ & 85 & $2202 a$ & 25,9 & 15,7 de \\
\hline Flávia & 42 & 54 & $119 \mathrm{~b}$ & 129 abcdef & 96 & $2199 a$ & 22,9 & $16,7 \mathrm{de}$ \\
\hline Jurema & 39 & 53 & $86 \mathrm{~b}$ & $164 \mathrm{a}$ & 92 & $2127 \mathrm{a}$ & 23,1 & 16,0 de \\
\hline Viçosa & 46 & 47 & $94 \mathrm{~b}$ & $72 \quad \mathrm{fg}$ & 93 & $2083 a$ & 22,4 & $17,5 \mathrm{~cd}$ \\
\hline CNPH 91-016 & 39 & 57 & $90 \mathrm{~b}$ & 103 bcdefg & 96 & $1871 \mathrm{a}$ & 19,5 & $21,0 \mathrm{~b}$ \\
\hline Luiza & 39 & 53 & $112 \mathrm{~b}$ & $143 \mathrm{abcd}$ & 92 & $1812 \mathrm{a}$ & 19,7 & $16,2 \mathrm{de}$ \\
\hline Ivete & 39 & 54 & $174 \mathrm{a}$ & defg & 93 & $1808 \mathrm{a}$ & 19,4 & 16,7 de \\
\hline Triofin & 42 & 54 & $110 \mathrm{~b}$ & 132 abcde & 96 & $1772 \mathrm{a}$ & 18,5 & $18,0 \mathrm{~cd}$ \\
\hline CNPH 91-025 & 39 & 51 & $83 \mathrm{~b}$ & 131,abcde & 90 & $1747 \mathrm{a}$ & 19,4 & $19,7 \mathrm{bc}$ \\
\hline Maria & 42 & 50 & $95 \mathrm{~b}$ & 128 abcdef & 92 & $1584 a$ & 17,2 & 16,2 de \\
\hline Verde Templana & 39 & 32 & $93 \mathrm{~b}$ & $157 \mathrm{ab}$ & 71 & $1509 a$ & 21,3 & $20,7 \mathrm{bc}$ \\
\hline Média & 40,6 & 50,9 & 102,3 & 121,4 & 91,4 & 1989,1 & 21,6 & 17,7 \\
\hline C.V.(\%) & - & - & 16,6 & 18,2 & - & 21,0 & - & 6,3 \\
\hline
\end{tabular}

*/ Médias seguidas da mesma letra nas colunas não diferem significativamente entre si a 5\% de probabilidade pelo teste de Tukey.

1/ Do início da floração à colheita.

2/ Tomada no vageamento. Média de 10 plantas.

3/ Rendimento dividido pelo ciclo de vida (emergência à floração) da cultivar ou linhagem.

\section{RESULTADOS E DISCUSSÃO}

\section{Ensaio de 1995}

A emergência das plântulas deu-se com seis dias. As cultivares precoces Majestic e Verde Templana demoraram 23 dias da emergência ao início da floração (Tabela 2). As demais cultivares e linhagens levaram entre 36 dias (linhagem 93-020) e 45 dias (cultivar Triofin) para florir. Em média, a duração do período vegetativo (emergência ao início da floração) foi semelhante à do período reprodutivo (início da floração à colheita). No entanto, as cultivares que floriram precocemente e a linhagem CNPH 93-020 apresentaram período reprodutivo bem mais longo que o vegetativo, enquanto as cultivares Marina e Maria demoraram mais tempo no período vegetativo. A cultivar Majestic apresentou o menor ciclo de vida (58 dias entre a emergência e a colheita), seguida da Verde Templana (63 dias). As demais cultivares foram colhidas entre 82 e 89 DAE.
Houve diferença significativa entre as médias de altura de plantas, que variaram de $60 \mathrm{~cm}$ (cultivar Majestic) a 164 $\mathrm{cm}$ (cultivar Ivete) (Tabela 2). O estande final médio foi de 117,8 plantas $/ 2,4 \mathrm{~m}^{2}$, ou seja, aproximadamente 491 mil plantas/ha, mas ele variou de 262 mil plantas/ha (linhagem CNPH 86/083) a 642 mil plantas/ha (cultivar Verde Templana). Em geral, o estande esteve abaixo do considerado ideal: entre 500 e 1.200 mil plantas/ha, dependendo da cultivar (Giordano, 1989b).

As cultivares precoces Majestic e Verde Templana apresentaram rendimento médio superior a $2.000 \mathrm{~kg} / \mathrm{ha}$ (Tabela 2). A média da cultivar Majestic, no entanto, não diferiu significativamente das médias das cultivares ou linhagens Verde Templana, Jurema, CNPH 93-020, Bolero, CNPH 91-025 e Polo PG1. A cultivar Viçosa apresentou a menor média de rendimento $(656 \mathrm{~kg} /$ ha), a qual não diferiu significativamente das médias de 11 cultivares e linhagens, incluída a cultivar mais plantada em Minas Gerais, a Mikado. Houve cor- relação negativa entre o período vegetativo e o rendimento $(\mathrm{r}=-0,75 * *)$, entre o ciclo de vida e o rendimento $(\mathrm{r}=$ $\left.-0,73^{* *}\right)$ e entre a altura de plantas e o rendimento $\left(\mathrm{r}=-0,55^{*}\right)$. Ou seja, as cultivares mais precoces e com ramas mais curtas geralmente foram mais produtivas. Isso parece indicar que as condições climáticas em 1995 favoreceram as cultivares mais precoces.

\section{Ensaio de 1997}

A emergência deu-se aos nove dias após o plantio. Em geral, as cultivares e linhagens iniciaram o florescimento um pouco mais cedo neste ensaio (Tabela 3) que no anterior (Tabela 2). A cultivar Verde Templana teve comportamento diferente do das outras cultivares e linhagens, iniciando o florescimento 13 dias mais tarde que em 1995. Não se encontrou explicação para tal fato. A duração do período reprodutivo foi mais longa que a verificada no ensaio de 1995. As temperaturas mais baixas verificadas durante a fase reprodutiva da ervilha em 1997 (Tabela 1) podem ter sido o principal fator responsável por 
isso. As temperaturas relativamente mais baixas nos meses de maio e junho, no entanto, não alongaram o período vegetativo. A cultivar Verde Templana teve comportamento distinto do das outras cultivares também quanto ao período reprodutivo: ele foi oito dias mais curto que o observado em 1995. Por causa do período vegetativo relativamente mais longo, o seu ciclo de vida foi mais longo (71 dias) neste ensaio.

Novamente a cultivar Ivete apresentou as plantas mais altas $(174 \mathrm{~cm})$. Esta média diferiu significativamente das médias das demais cultivares e linhagens (Tabela 3 ). Oito cultivares tiveram rendimentos acima de $2.000 \mathrm{~kg} / \mathrm{ha}$, mas não houve diferença significativa entre as médias de rendimento dos tratamentos. A cultivar Dileta, apesar do baixo estande final (279 mil plantas/ha) teve a maior média de rendimento $(2.363 \mathrm{~kg} /$ ha), mas a maior média de taxa de produção foi alcançada pela cultivar Amélia (25,9 kg/ha/dia) (Tabela 3).Em 1995, as cultivares Dileta e Amélia não estiveram entre as mais produtivas. A menor média de rendimento foi verificada com a Verde Templana, que, em 1995, esteve entre as mais produtivas. A temperatura relativamente mais baixa em 1997 (Tabela 1) pode ter sido o motivo da maior média de rendimento $(1.989 \mathrm{~kg} /$ ha), da menor variação entre os rendi- mentos dos tratamentos e da nãosignificância das correlações que haviam sido significativas em 1995.

Com exceção da Verde Templana, o peso de 100 grãos foi maior em 1997 que em 1995 (Tabelas 2 e 3). As temperaturas mais baixas em 1997 durante a fase de enchimento de grãos, em relação às verificadas em 1995 (Tabela 1), podem ter favorecido esse componente do rendimento dos materiais de ciclo de vida normal.

Os rendimentos alcançados nos dois ensaios foram superiores aos obtidos na região sul de Minas Gerais (Guaresqui, 1982) e semelhantes aos normalmente alcançados nas lavouras conduzidas com boa tecnologia no Alto Paranaíba e no Triângulo Mineiro. Este estudo foi realizado em ano de temperaturas mais altas (1995) e mais baixas (1997) que as temperaturas médias verificadas no período de 1989-94 (Tabela 1). Portanto, o clima nesses dois anos representou bem as variações climáticas do local. Por isso, infere-se que o cultivo da ervilha é uma alternativa viável ao cultivo do feijão-comum no Norte de Minas Gerais onde as condições edafoclimáticas forem semelhantes às de Janaúba. Para a seleção de cultivares mais adaptadas às condições edafoclimáticas da região, há necessidade de estudo mais abrangente que o presente.

\section{LITERATURA CITADA}

COUTO, F.A. D'A. Aspectos históricos e econômicos da cultura da ervilha. Informe Agropecuário, Belo Horizonte, v. 14, n. 158, p. 5-7, 1989.

GALRÃO, E.Z.; VARGAS, M.A.T.; LOBATO, E.; OLIVIEIRA, H.A. de. Épocas de semeadura de ervilha (Pisum sativum) para produção de sementes no Brasil Central. Pesquisa Agropecuária Brasileira, Brasília, v. 9, p. 117-119, 1974.

GIORDANO, L de B. Cultivares de ervilha. Informe Agropecuário, Belo Horizonte, v. 14, n. 158 , p. $22-25,1989$ a.

GIORDANO, L de B. Manejo e tratos culturais da ervilha. Informe Agropecuário, Belo Horizonte, v. 14 , n. 158 , p. 26-27, 1989 b.

GUARESQUI, J. de A. Efeitos de cultivares, épocas, espaçamentos e densidades de plantio sobre algumas características agronômicas da ervilha (Pisum sativum L.) em solos de baixada no sul de Minas Gerais. 1982. 87 p. (Tese mestrado).

REIS, N.V.B. dos; OLIVEIRA, C.A. da S.; GIORDANO, L.B. Graus-dia e época de plantio para produção de grãos secos de ervilha. Horticultura Brasileira, Brasília, v. 7, n. 2, p. 12-14, 1989. 